\title{
Fourier Transformation on Model Fitting for Pakistan Inflation Rate
}

\author{
Anam Iqbal (Corresponding author) \\ Dept. of Statistics, Govt. Post Graduate College (w), Sargodha, Pakistan \\ Tel: 92-321-603-4232Ｅ-mail: anammughal343@gmail.com \\ Basheer Ahmad \\ Dept. of Management Sciences, Iqra University, Islamabad, Pakistan \\ Tel: 92-322-656-5140Ｅ-mail: drbasheer@iqraisb.edu.pk

\begin{abstract}
Kanwal Iqbal
University of Management and Technology, Lahore, Pakistan

Tel: 92-336-750-2158Ｅ-mail: F2017204003@umt.edu.pk
\end{abstract} \\ Dept. of Quantitative Method SBE (School of Business and Economics)
}

Asad Ali

Dept. of Statistics, University of Sargodha, Sargodha, Pakistan

Tel: 92-304-161-1166_E-mail: ranaasadali23@gmail.com

Received: October 25, 2017 Accepted: November 10, 2017

doi:10.5296/ber.v8i1.12052ＵRL: https://doi.org/10.5296/ber.v8i1.12052

\begin{abstract}
Inflation is one of the serious economic indicators in Pakistan. Inflation can be crawling, walking, running, hyper and stagflation according to nature. To model monthly inflation rate in Pakistan periodogram analysis and frequency domain analysis which is also known as Fourier analysis or spectral analysis is used. After analyzing the data, inflation cycle length is observed and appropriate Fourier series models are fitted to the data. Monthly inflation rate is also analyzed by Auto Regressive Integrated Moving average (ARIMA). Further, models are
\end{abstract}


compared and it is found that Fourier series models are more suitable to forecast inflation rate of Pakistan.

Keywords: Inflation, Periodogram, Fourier Series Models, ARIMA Models, Stationarity, Root Mean Square Error, Mean Absolute Error

\section{Introduction}

Inflation is a situation in which price level increases and purchasing power decreases. There are certain elements cause the rise of inflation such as increase in population, increase in demand, lack of supply, development expenditures and constant low production due to some social, political, climatic, national or international situations. Increase in inflation rate gives birth to unemployment, poverty, unfair distribution, poor labour force and social evils. So, for economic growth of a country, it is important to analyze inflation rate of a country.

Time series is the collection of observation with respect to time or space. Time series analysis is also known as time domain analysis. Box and Jenkins (1976) methodology come under time domain analysis. Time series may contain trend, seasonality, cyclic and random component. Therefore it is important to explore the stationarity of data. A stationary series has a wave-like pattern as it has constant mean and constant variance. Waves have a period which is the distance between peaks or time between two peaks of a wave. Frequency is the closely related property of the wave period and is just the proportion of cycle that occurs during one observation. Frequency domain is used to analyze the data with respect to frequency.

Transformation is very important in frequency domain analysis and is used to convert a time domain function into a frequency domain. Fourier transformation found by great mathematician Joseph Fourier (1822) is the most commonly used transformation in frequency domain analysis. This frequency domain analysis is also known as spectral analysis or Fourier analysis. In this paper frequency domain approach with periodogram analysis is used to model the monthly inflation rate. Model based on spectral analysis and model based on Box-Jenkins methodology are also compared.

\section{Literature Review}

Etuk (2012) presented time series analysis of Nigerian monthly inflation rates and fitted a multiplicative seasonal autoregressive integrated moving average model. He showed that the model is adequate and forecasts are agreed closely with observations. Raza, Javed and Naqvi (2013) discussed the impact of inflation on economic growth of Pakistan and estimated short run and long run relationship between inflation and economic growth. They suggested that government should maintain inflation in single digit which is favorable for economic growth.

Ekpenyong, John, Omekara and Peter (2014) proposed the application of periodogram analysis and Fourier analysis to model inflation rates in Nigeria. The main objective of the study was to identify inflation cycles and fit the appropriate model to forecast future values. Konarasinghe and Abeynayake (2015) suggested a study based on Fourier transformation on model fitting for Sri Lankan share market. They also analyzed the monthly returns by 
ARIMA (Auto Regressive Integrated Moving Average) and concluded that Fourier transformation along with multiple regression is suitable.

Konarasinghe, Abeynayake and Gunaratne (2015) proposed a model by using Box-Jenkins methodology or Auto-Regressive Integrated Moving Average (ARIMA) methodology to forecast Sri Lankan share market returns. Jere and Siyanga (2016) used Holt's exponential smoothing and Auto-Regressive Integrated Moving Average (ARIMA) models to forecast inflation rate of Zambia. They showed that the choice of Holt's exponential smoothing is as good as an ARIMA model.

Konarasinghe, Abeynayake and Gunaratne (2016) developed a model named as circular model based on Fourier transformation to forecast Returns of Sri Lankan share market. Thomson and Vuuren (2016) proposed Fourier transform analysis to determine the duration of South African business cycle which is measured by using log changes in nominal GDP (Gross Domestic Product). Three dominant cycles are used to forecast log monthly nominal GDP and the forecasts are compared with historical data. They found that Fourier analysis is more effective in estimating the business cycle length as well as in determining the position of the economy in the business cycle.

\section{Research Methodology}

The main objective of this study is to develop a significant model to forecast inflation rate in Pakistan. For this purpose, monthly data on CPI inflation rate from 2008 to 2016 is collected from (Pakistan Bureau of Statistics, n.d.). First periodogram analysis is used to find inflation cycle as inflation is affected by many factors which may cause seasonality and periodicity in the series. After determining the period or frequency of series, significance of selected period is tested by a test developed by Fisher (1929). Fourier series is then used to model inflation rate by utilizing selected frequency as Fourier frequency. Moreover, Box-Jenkins methodology is also used to model the data. By using accuracy measures both types of models are compared and it is found that model based on Fourier series is considering smaller deviation in Root Mean Square Error (RMSE), Mean Absolute Error (MAE) and Mean Absolute Percentage Error (MAPE).

\subsection{Periodogram Analysis}

Periodogram is a tool that partitions the total variance of a time series into component variances like ANOVA. The longer cycle shares large variance in the series. In general practice periods of cycles are not known then Periodogram is utilized to identify dominant cyclic behavior in the series. In periodogram analysis, time series can be viewed as

$$
Y_{t}=T_{t}+\sum_{i=1}^{N}\left(a_{i} \cos w_{i} t+b_{i} \sin w_{i} t\right)+\varepsilon_{t}
$$

where $T_{t}$ is trend, $N$ is total number of observations, $a_{i}$ and $b_{i}$ are coefficients, $w_{i}$ is angular frequency in radians and $\varepsilon_{t}$ is error term. The coefficients are calculated as 


$$
\begin{aligned}
& a_{i}=\frac{2}{N} \sum_{t=1}^{N}\left(Y_{t}-\hat{T}_{t}\right) \cos w_{i} t, \\
& b_{i}=\frac{2}{N} \sum_{t=1}^{N}\left(Y_{t}-\hat{T}_{t}\right) \sin w_{i} t .
\end{aligned}
$$

The calculated coefficients are then used to obtain Intensity or Periodogram ordinate at frequency $f_{i}$ as

$$
I\left(f_{i}\right)=\frac{2}{N}\left(a_{i}^{2}+b_{i}^{2}\right) \quad i=1,2, . q
$$

In case of even number of observations $N=2 q, q=N / 2$ and for odd number of observations $N=2 q+1, q=(N-1) / 2$. The period against the largest Intensity that is actually the largest sum of squares is selected as cycle period of series.

\subsection{A Significance Test for Periodic Component}

The variability in the sizes of sum of squares may be due to just sampling error. The largest ordinate must indicate strong periodicity even for white noise series. Therefore it is necessary to test the significance of largest periodic component in white noise. A test developed by Fisher (1929) provides a reasonable method for testing significance of such periodic components. To perform Fisher test $\mathrm{g}$ statistic is computed which is the ratio of largest sum of squares (or intensity ordinate) to the total sum of squares. Tables of critical values for this test statistic are given in Russell (1985). The null hypothesis of white noise series is rejected, if the value of $\mathrm{g}$ statistic is greater than critical value.

\subsection{Spectral Analysis}

The basic idea of spectral analysis is to transform the time domain series into frequency domain series, which determines the importance of each frequency in the original series. This target is achieved by using Fourier transformation.

The general Fourier series model that contain components of time series is given by

$$
Y_{t}=T_{t}+\sum_{i=1}^{k}\left(\alpha_{i} \cos i w t+\beta_{i} \sin i w t\right)+\varepsilon_{t}
$$

where

$\mathrm{w}=2 \pi \mathrm{f}$

$\mathrm{k}=\mathrm{n} / 2 \quad$ (In case of even number)

$\mathrm{k}=(\mathrm{n}-1) / 2 \quad$ (In case of odd number)

$\mathrm{n}$ is the number of observations per season or cycle length, $\mathrm{f}$ is the Fourier frequency or number of peaks in series, $\mathrm{k}$ is the harmonic of $\mathrm{w}$ (see Delurgio, 1998), $\mathrm{t}$ is the time index, $\alpha_{i}$ 


\section{Macrothink}

and $\beta_{i}$ are amplitudes which are estimated through multiple linear regression analysis.

\subsection{ARIMA}

Autoregressive integrated moving average models are presented by Box, Jenkins and Reinsel (1994). To achieve stationarity, if a series is differenced d times then the model will be $\operatorname{ARIMA}(\mathrm{p}, \mathrm{d}, \mathrm{q})$, where $\mathrm{p}$ denotes autoregressive terms and $\mathrm{q}$ denotes moving average terms. ARIMA model for a stationary time series is a linear equation in which predictors are lags of dependent variable and lags of error terms i.e.

$$
\phi_{p}(B) \Delta^{d} Y=\theta_{q}(B) \varepsilon_{t},
$$

where, $Y_{t}=$ present value, $d=$ difference, $B=$ backshift operator, $\varepsilon_{t}=$ present error term

\section{Results and Discussion}

Time series plot of original inflation rate in Pakistan is constructed. Figure 1 shows that there exist trend, seasonality and cyclical variations in the series but the length of the cycle is not confirmed.

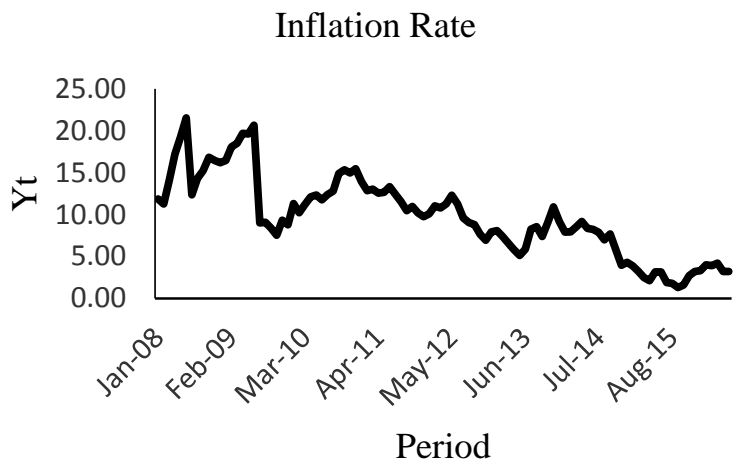

Figure 1. Original Series of Inflation Rates

In this study first stationarity of the series is examined by using ACF (Autocorrelation Function), PACF (Partial Autocorrelation Function) and ADF (Augmented Dicky Fuller) test and it is found that series is not stationary. As figure 1 indicates there exist trend therefor to make such a time series stationary, the trend is estimated and then removed from the series.

\subsection{Fitting Trend Model}

The estimated trend equation is given by

$\hat{T}_{t}=16.927-0.1387 t$ 
Table 1 . Summary of trend model

\begin{tabular}{|c|c|c|c|c|}
\hline Predictor & coef & SE coef & $\mathrm{t}$ & $\mathrm{P}$ \\
\hline Constant & 16.9270 & 0.4992 & 33.91 & 0.000 \\
\hline $\mathrm{T}$ & -0.1387 & 0.0084 & -16.48 & 0.000 \\
\hline $\mathrm{S}=2.50222$ & $\mathrm{R}-\mathrm{Sq}=73.1 \%$ & $\mathrm{R}-\mathrm{Sq}(\mathrm{adj})=72.8 \%$ \\
\hline
\end{tabular}

Table 1 shows that both the parameters in the trend model are significant.

\subsection{Periodogram Analysis}

After removing trend from the series, de-trended series is used to estimate seasonal component. By using equation (2), (3) and (4) intensities at various frequencies are obtained as given in Table 2.

Table 2. Frequencies, Periods and Intensities

\begin{tabular}{|c|c|c|c|c|c|}
\hline freq & $\mathrm{P}$ & $\mathrm{Pdg}$ & freq & $\mathrm{P}$ & Pdg \\
\hline 0 & & 0 & 0.254902 & 3.923077 & 2.469466 \\
\hline 0.009804 & 102 & 17.82893 & 0.264706 & 3.777778 & 2.571481 \\
\hline 0.019608 & 51 & 0.283872 & 0.27451 & 3.642857 & 4.361273 \\
\hline 0.029412 & 34 & 151.7146 & 0.284314 & 3.517241 & 3.985825 \\
\hline 0.039216 & 25.5 & 5.061672 & 0.294118 & 3.4 & 1.131958 \\
\hline 0.04902 & 20.4 & 143.5882 & 0.303922 & 3.290323 & 0.115284 \\
\hline 0.058824 & 17 & 24.33793 & 0.313725 & 3.1875 & 0.848861 \\
\hline 0.068627 & 14.57143 & 6.144949 & 0.323529 & 3.090909 & 4.099034 \\
\hline 0.078431 & 12.75 & 13.55495 & 0.333333 & 3 & 4.243186 \\
\hline 0.088235 & 11.33333 & 17.27606 & 0.343137 & 2.914286 & 3.418537 \\
\hline 0.098039 & 10.2 & 27.54437 & 0.352941 & 2.833333 & 1.415018 \\
\hline 0.107843 & 9.272727 & 63.83039 & 0.362745 & 2.756757 & 1.373335 \\
\hline 0.117647 & 8.5 & 3.69523 & 0.372549 & 2.684211 & 1.026038 \\
\hline 0.127451 & 7.846154 & 1.240284 & 0.382353 & 2.615385 & 1.869164 \\
\hline 0.137255 & 7.285714 & 6.553623 & 0.392157 & 2.55 & 3.213267 \\
\hline 0.147059 & 6.8 & 4.288788 & 0.401961 & 2.487805 & 3.215139 \\
\hline 0.156863 & 6.375 & 17.12196 & 0.411765 & 2.428571 & 2.99018 \\
\hline 0.166667 & 6 & 23.81014 & 0.421569 & 2.372093 & 2.466381 \\
\hline 0.176471 & 5.666667 & 14.43552 & 0.431373 & 2.318182 & 2.288237 \\
\hline 0.186275 & 5.368421 & 4.424012 & 0.441176 & 2.266667 & 0.927199 \\
\hline 0.196078 & 5.1 & 3.554464 & 0.45098 & 2.217391 & 0.390481 \\
\hline 0.205882 & 4.857143 & 3.682635 & 0.460784 & 2.170213 & 0.329865 \\
\hline 0.215686 & 4.636364 & 0.798868 & 0.470588 & 2.125 & 1.620553 \\
\hline 0.22549 & 4.434783 & 6.765822 & 0.480392 & 2.081633 & 3.01465 \\
\hline 0.235294 & 4.25 & 2.518789 & 0.490196 & 2.04 & 3.122662 \\
\hline 0.245098 & 4.08 & 3.450255 & 0.5 & 2 & 4.191004 \\
\hline
\end{tabular}




\section{IIMacrothink}

Business and Economic Research

ISSN 2162-4860 2018, Vol. 8, No. 1

Table 2 shows that period and frequency corresponding to largest intensity are $\mathrm{n}=34$ and $\mathrm{f}=$ 0.02941 . Here frequency is just the inverse of period. Thus the period of cycle or long-term inflation cycle is 34 months. This shows that inflation rate is high during 2008-01 to 2010-10. The short-term inflation cycle identified by second largest intensity is 20 months that is from 2010-11 to 2013-06.

\subsection{Significance Test of Periodic Component}

As Fisher test statistic value in Table 3 is greater than the critical value so the null hypothesis of white noise is rejected and the selected period is significant.

Table 3. Output of Significance test

\begin{tabular}{|l|c|c|}
\hline & G statistic & Critical value \\
\hline Fisher Test & 0.2415 & 0.126 \\
\hline
\end{tabular}

\subsection{Estimation of Seasonal Component}

Since the number of observations is even therefore,

$$
K=\frac{n}{2}=\frac{34}{2}=17
$$

and

$w=2 \times \pi \times 0.02941$

Hence the seasonal model is given by

$$
Y_{t}=\sum_{i=1}^{17}\left(\alpha_{i} \cos i w t+\beta_{i} \sin i w t\right)
$$

The parameters of this model are estimated by the least square method. 
Table 4. Parameter Estimation in seasonal component

\begin{tabular}{|c|c|c|c|c|c|c|c|c|c|}
\hline Predictor & Coef & SE coef & $\mathrm{t}$ & $\mathrm{p}$ & Predictor & Coef & SE coef & $\mathrm{t}$ & $\mathrm{p}$ \\
\hline coswt & 0.2011 & 0.3326 & 0.60 & 0.547 & $\sin 9 \mathrm{wt}$ & -0.1804 & 0.3326 & -0.54 & 0.589 \\
\hline sinwt & 1.7138 & 0.3325 & 5.15 & 0.000 & $\cos 10 \mathrm{wt}$ & 0.0979 & 0.3326 & 0.29 & 0.769 \\
\hline $\cos 2 \mathrm{wt}$ & 0.5942 & 0.3326 & 1.79 & 0.078 & $\sin 10 \mathrm{wt}$ & -0.1098 & 0.3327 & -0.33 & 0.742 \\
\hline $\sin 2 \mathrm{wt}$ & -0.3602 & 0.3325 & -1.08 & 0.283 & $\cos 11 \mathrm{wt}$ & 0.1520 & 0.3326 & 0.46 & 0.649 \\
\hline $\cos 3 \mathrm{wt}$ & -0.5690 & 0.3326 & -1.71 & 0.092 & $\sin 11 \mathrm{wt}$ & -0.2342 & 0.3328 & -0.70 & 0.484 \\
\hline $\sin 3 \mathrm{wt}$ & 0.0970 & 0.3325 & 0.29 & 0.771 & $\cos 12 \mathrm{wt}$ & 0.1696 & 0.3326 & 0.51 & 0.612 \\
\hline $\cos 4 \mathrm{wt}$ & 0.2673 & 0.3326 & 0.80 & 0.424 & $\sin 12 \mathrm{wt}$ & 0.0322 & 0.3330 & 0.10 & 0.923 \\
\hline $\sin 4 \mathrm{wt}$ & -0.0619 & 0.3325 & -0.19 & 0.853 & $\cos 13 \mathrm{wt}$ & 0.1959 & 0.3326 & 0.59 & 0.558 \\
\hline $\cos 5 \mathrm{wt}$ & -0.1403 & 0.3326 & -0.42 & 0.674 & $\sin 13 \mathrm{wt}$ & -0.0045 & 0.3332 & -0.01 & 0.989 \\
\hline $\sin 5 \mathrm{wt}$ & -0.2481 & 0.3325 & -0.75 & 0.458 & $\cos 14 \mathrm{wt}$ & -0.1704 & 0.3326 & -0.51 & 0.610 \\
\hline $\cos 6 \mathrm{wt}$ & 0.4640 & 0.3326 & 1.39 & 0.168 & $\sin 14 \mathrm{wt}$ & 0.1847 & 0.3339 & 0.55 & 0.582 \\
\hline $\sin 6 \mathrm{wt}$ & -0.2661 & 0.3325 & -0.80 & 0.426 & $\cos 15 \mathrm{wt}$ & 0.1041 & 0.3326 & 0.31 & 0.755 \\
\hline $\cos 7 \mathrm{wt}$ & 0.0541 & 0.3326 & 0.16 & 0.871 & $\sin 15 \mathrm{wt}$ & -0.0645 & 0.3356 & -0.19 & 0.848 \\
\hline $\sin 7 \mathrm{wt}$ & -0.2593 & 0.3326 & -0.78 & 0.438 & $\cos 16 \mathrm{wt}$ & -0.0459 & 0.3325 & -0.14 & 0.891 \\
\hline $\cos 8 \mathrm{wt}$ & 0.2135 & 0.3326 & 0.64 & 0.523 & $\sin 16 \mathrm{wt}$ & -0.1154 & 0.3450 & -0.33 & 0.739 \\
\hline $\sin 8 \mathrm{wt}$ & 0.0808 & 0.3326 & 0.24 & 0.809 & $\cos 17 \mathrm{wt}$ & 0.4074 & 0.4954 & 0.82 & 0.414 \\
\hline $\cos 9 \mathrm{wt}$ & -0.1208 & 0.3326 & -0.36 & 0.717 & $\sin 17 \mathrm{wt}$ & 28.55 & 47.13 & 0.61 & 0.547 \\
\hline
\end{tabular}

Table 4 indicates that sinwt is significant at $5 \%$ level of significance and sinwt, cos $2 \mathrm{wt}$, $\cos 3 \mathrm{wt}$ are significant at $10 \%$ level of significance. So the estimated seasonal models are given by

$$
\begin{gathered}
\Delta \hat{Y}_{t}=1.7138 \sin w t \\
\Delta \hat{Y}_{t}=1.7138 \sin w t+0.5942 \cos 2 w t-0.5690 \cos 3 w t
\end{gathered}
$$

Since $\Delta \mathrm{Y}_{t}^{\text {资 }} Y_{t}-T$

By exploring the randomness of error term with the help of ACF and PACF it is found that error term is not random. So first order autoregressive is used.

Table 5. Summary of first order autoregressive

\begin{tabular}{|c|c|c|c|c|}
\hline Predictor & Coef & SE coef & $\mathrm{t}$ & $\mathrm{P}$ \\
\hline$\varepsilon_{\mathrm{t}-1}$ & 0.65893 & 0.07242 & 9.1 & 0 \\
\hline \multicolumn{5}{|c|}{$\mathrm{s}=1.41653$} \\
\hline
\end{tabular}

Table 5 presents that the parameter estimate of error term is significant in model.

$$
\hat{\varepsilon}_{t}=0.658822 \varepsilon_{t-1}
$$




\subsection{General Fourier Series Model}

The general models which consist estimated trend, estimated seasonal component and error component may be

$$
\begin{gathered}
\hat{Y}_{t}=16.927-0.1387 t+1.7138 \sin w t+0.65893 \varepsilon_{t-1} \\
\hat{Y}_{t}=16.927-0.1387 t+1.17138 \sin w t+0.5942 \cos 2 w t-0.5690 \cos 3 w t+0.65893 \varepsilon_{t-1}
\end{gathered}
$$

Model (10) and model (11) are found to be overall significant. The residuals of both models are also found to be independently and normally distributed.

Table 6. Summary of Fourier series Models

\begin{tabular}{|c|c|c|c|}
\hline Model & RMSE & MAE & MAPE \\
\hline Model (10) & 1.68 & 1.16 & $15 \%$ \\
\hline model (11) & 1.57 & 1.03 & $13 \%$ \\
\hline
\end{tabular}

Table 6 shows that RMSE, MAE and MPE for both models are small.

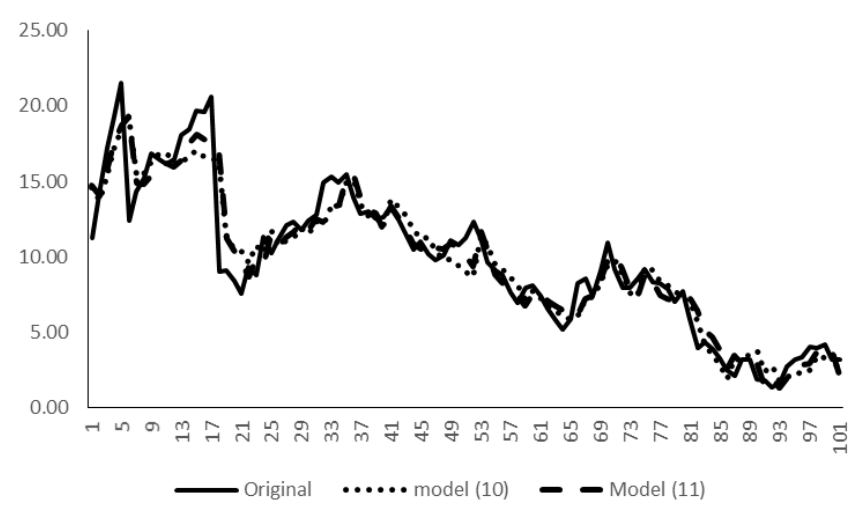

Figure 2. Plot of actual and estimates

Figure 2 reveals that estimated values of both models are very close to actual values.

\subsection{ARIMA Models on Inflation Rate}

Time series plot of inflation rate shows that series is non-stationary. After taking the first difference series becomes stationary and stationarity is confirmed through correlogram and ADF test. The identification of AR and MA is done through correlogram and ARIMA models of different orders are fitted to the data as given in Table 7.

Table 7. Summary of ARIMA Models

\begin{tabular}{|c|c|c|c|}
\hline Model & RMSE & MSE & MAPE \\
\hline$(12,1,16)$ & 2.52 & 1.94 & $34 \%$ \\
\hline$(16,1,16)$ & 3.03 & 2.20 & $40 \%$ \\
\hline
\end{tabular}

ARIMA models are found to be overall significant. RMSE, MSE and MAPE of both models 
are small. The residuals of both models are also independently and normally distributed. From the output of Table 6 and Table 7, it can be seen that Fourier series models are good fitted as compare to ARIMA models.

\section{Conclusion}

Using periodogram analysis to study inflation rate in Pakistan, it has been found that inflation is much affected by periodic or cyclical variation as long-term inflation cycle is 34 months and short-term inflation cycle is 20 months for the period under study. Fourier series models have been developed to forecast inflation rate in Pakistan. ARIMA models have also been fitted to the monthly inflation rate in Pakistan. It has been observed that accuracy measures RMSE, MAE, MAPE for both types of fitted models are good and residuals are normally and independently distributed. So both methods can be used to forecast Pakistan inflation rate but it is identified that Fourier series models have more effective accuracy measures as compare to ARIMA models.

\section{References}

Box, G. P. E., \& Jenkins, G. M. (1976). Time series analysis: Forecasting and control. San Francisco: Holden-Day.

Box, G. P. E., Jenkins, G. M., \& Reinsel, G. (1994). Time series analysis: Forecasting and control. New Jersey, NJ: Prentice Hall.

Ekpenyong, John, E., Omekara, C. O., \& Peter, E. M. (2014). Modeling inflation rates using periodogram and fourier series analysis methods: The Nigerian case. International journal of African \& Asian studies, 4, 49-62.

Etuk, E. H. (2012). Predicting inflation rates of Nigeria using a seasonal Box-Jenkins model. Journal of statistical and econometric methods, 1(3), 27-37.

Fisher, R. A. (1929). Tests of significance in harmonic analysis. Proceedings of the royal society of London, 125(796), 54-59. https://doi.org/10.1098/rspa.1929.0151

Fourier, J. (1822). The analytical theory of heat. New York: Dover publications.

Jere, S., \& Siyanga, M. (2016). Forecasting inflation rate of Zambia using Holt's exponential smoothing. Open journal of Statistics, 6, 363-372. https://doi.org/10.4236/ojs.2016.62031

Konarasinghe, W. G. S., \& Abeynayake, N. R. (2015). Fourier transformation on model fitting for Sri Lankan share market returns. Global journal for research analysis, 4(1), 159-161.

Konarasinghe, W. G. S., Abeynayake, N. R., \& Gunaratne, L. (2015). ARIMA models on forecasting Sri Lankan share market returns. International journal of novel research in Physics Chemistry and Mathematics, 2(1), 6-12.

Konarasinghe, W. G. S., Abeynayake, N. R., \& Gunaratne, L. (2016). Circular model on forecasting returns of Sri Lankan Share market. International journal of novel research in Physics Chemistry and Mathematics, 3(1), 49-56. 


\section{Macrothink}

Business and Economic Research

ISSN 2162-4860 2018, Vol. 8, No. 1

Pakistan Bureau of Statistics. (n.d.). Publications. Retrieved from http://www.pbs.gov.pk/publications

Raza, S. H., Javed, M. R., \& Naqvi, S. A. (2013). Economic growth \& inflation: A time series analysis of Pakistan. International journal of innovative research and development, 2(6), 689-703.

Russell, R. H. (1985). Significance tables for the results of fast fourier transforms. British journal of mathematical and statistical psychology, 38(1), 116-119.

https://doi.org/10.1111/j.2044-8317.1985.tb00820.x

Delurgio, S. (1998). Forecasting principles and applications. United States of America, USA: Irwin McGraw-Hill.

Thomson, D., \& Vuuren, G. V. (2016). Forecasting the South African business cycle using fourier analysis. International business and economics research journal, 15(4), 175-192. https://doi.org/10.19030/iber.v15i4.9755

\section{Copyright Disclaimer}

Copyright for this article is retained by the author(s), with first publication rights granted to the journal.

This is an open-access article distributed under the terms and conditions of the Creative Commons Attribution license (http://creativecommons.org/licenses/by/3.0/). 